Mens

Revue d'histoire intellectuelle et culturelle

\title{
Introduction : L'étude des transferts culturels en histoire culturelle
}

\section{Stéphanie Danaux et Nova Doyon}

Volume 12, numéro 2, printemps 2012

Enjeux et modalités des transferts culturels dans la vie artistique canadienne-française de la première moitié $d u \mathrm{XX}^{\mathrm{e}}$ siècle

URI : https://id.erudit.org/iderudit/1013871ar

DOI : https://doi.org/10.7202/1013871ar

Aller au sommaire du numéro

Éditeur(s)

Centre de recherche en civilisation canadienne-française

ISSN

1492-8647 (imprimé)

1927-9299 (numérique)

Découvrir la revue

Citer ce document

Danaux, S. \& Doyon, N. (2012). Introduction : L'étude des transferts culturels en histoire culturelle. Mens, 12(2), 7-16. https://doi.org/10.7202/1013871ar 


\title{
Dossier
}

\section{Enjeux et modalités des transferts culturels dans la vie artistique canadienne-française de la première moitié du $\mathrm{XX}^{\mathrm{e}}$ siècle}

\section{Introduction : L'étude des transferts culturels en histoire culturelle}

\author{
Stéphanie Danaux \\ Université Pierre-Mendès-France Grenoble 2
}

Nova Doyon

Centre de recherche interuniversitaire sur la littérature et la culture québécoises de l'Université Laval

L'affirmation de l'histoire culturelle comme champ historiographique se produit au cours des années 1980, lorsque la publication de textes à l'ambition théorique a permis de conceptualiser cette approche, notamment en France sous les plumes de Roger Chartier et Pascal Ory ${ }^{1}$. D'emblée, le champ d'investigation de l'histoire culturelle est

\footnotetext{
1 Roger Chartier, «Histoire intellectuelle et histoire des mentalités : trajectoires et questions ", Revue de synthèse, troisième série, $\mathrm{n}^{\text {os }} 111-112$ (juillet-décembre 1983), p. 277-307; Roger Chartier, "Le monde comme représentation », Annales ESC, $44^{\mathrm{e}}$ année, $\mathrm{n}^{\circ} 6$ (novembre-décembre 1989), p. 1505-1520; Pascal Ory, «L'histoire culturelle de la France contemporaine, question et questionnement ", Vingtième Siècle : revue d'histoire, $\mathrm{n}^{\circ} 16$ (octobre-décembre 1987), p. 67-82.
} 
apparu particulièrement vaste. Faisant fi des distinctions académiques traditionnelles entre culture savante et culture populaire, cette approche s'intéresse à l'étude des objets en société, le terme " objet » étant entendu dans son sens le plus large. Il couvre ainsi toutes les formes d'expression culturelle, "qu'il s'agisse d'une chanson des rues, d'un traité de philosophie ou d'une course cycliste ${ }^{2}$ ». Ces objets, que l'on qualifiera de biens culturels ou de pratiques culturelles, peuvent donc être matériels ou immatériels. Par ailleurs, le caractère de durée de ceux-ci est parfois éphémère, comme peut l'être celui d'une fête, d'une affiche publicitaire, d'une caricature, d'une mode vestimentaire ou encore d'une programmation radiophonique. Ces différents objets ont en commun de constituer des phénomènes symboliques envisagés dans leur dimension collective. L'histoire culturelle s'intéresse donc, selon les mots de Pascal Ory, à «l'ensemble des représentations collectives propres à une société ${ }^{3}$ ". En termes de pratique historienne, l'histoire culturelle peut donc être définie comme une " histoire sociale des représentations ${ }^{4}$ ». C'est le regard que ce champ porte sur les phénomènes envisagés, autrement dit l'intégration sociale de ces objets dans la vie culturelle, qui nous intéresse.

L'une des notions qui semble avoir grandement nourri la recherche en histoire culturelle est celle de transfert culturel, développée par les germanistes Michel Espagne et Michael Werner à travers plusieurs textes à caractère programmatique, pour étudier les emprunts que les cultures française et allemande se sont mutuellement faits

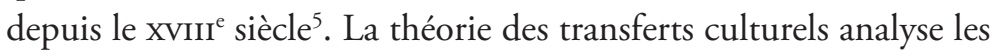
mouvements de personnes, d'objets, de discours ou d'esthétiques

2 Pascal Ory, L'histoire culturelle, Paris, Presses universitaires de France, [2004] 2007, coll. "Que sais-je?", p. 10.

3 Ibid., p. 8.

4 Ibid., p. 13.

5 Michel Espagne et Michael Werner (dir.), Transferts : les relations interculturelles dans l'espace franco-allemand (XVIII'-XIX' siècles), Paris, Recherches sur les civilisations, 1988, p. 5. Voir aussi Michel Espagne, Transferts culturels franco-allemands, Paris, Presses universitaires de France, 1999. 
entre deux aires culturelles - qui ne sont pas forcément des pays - à travers les différentes étapes de sélection, de médiation et de réception des références étrangères par la société d'accueil. Ce principe méthodologique met l'accent, d'une part, sur les processus de transformation, d'adaptation et d'appropriation, voire de re-sémantisation, des pratiques culturelles opérés au cours de ce mouvement et, d'autre part, sur les types de médiation qui permettent le transfert : quand ces médiateurs sont humains (groupes ou individus comme des artistes, auteurs, éditeurs, libraires, professeurs, etc.), on parle d'agents ou de passeurs culturels; quand ils sont d'ordre matériel (livres, revues, œuvres, etc.), il est plutôt question de supports du transfert. L'étude des transferts culturels n'insiste cependant pas tant sur les modalités du déplacement lui-même que sur les stratégies et les enjeux qu'il masque, liés aux médiateurs, mais aussi aux contextes de départ et d'accueil. Même si la relation entre deux systèmes culturels est généralement asymétrique, cette approche a la particularité de mettre en valeur le caractère actif des échanges entre les cultures émettrice et réceptrice : il y a sélection, transformation et appropriation des objets et des pratiques culturels selon la sensibilité de chaque récepteur individuel, mais aussi en fonction des besoins de la société d'accueil et des motivations conjoncturelles (légitimation ou subversion d'un pouvoir, d'une position, d'une idéologie). À cet égard, l'étude des transferts culturels s'intéresse autant aux emprunts qu'aux rejets, et donc aux points de rupture entre deux formations culturelles. Loin d'être un phénomène passif, le transfert culturel contribue à la création d'une production toujours originale et inédite. Il repose sur le désir d'affirmation identitaire de la culture d'accueil, lequel révèle généralement, selon les cas, une volonté de différenciation ou d'intégration à un ensemble culturel plus vaste dont la légitimité est reconnue.

À la base, l'étude des transferts culturels repose sur deux constats : d'une part, celui du caractère composite de la culture et, d'autre part, celui d'une distinction, non hiérarchisée, entre les cultures émettrice et réceptrice. Cette méthode offre ainsi un changement de perspective considérable par rapport à l'étude des influences telle qu'elle se 
pratiquait, notamment, en histoire littéraire, selon une méthode développée au tournant du $\mathrm{xx}^{\mathrm{e}}$ siècle par l'historien de la littérature et critique littéraire français Gustave Lanson. Celle-ci établissait systématiquement une hiérarchie entre les cultures, car c'est par la lorgnette de la littérature française hégémonique que l'on évaluait la valeur des productions culturelles étrangères, selon leur capacité à reproduire, sans réelle innovation, les modèles esthétiques français. Cette vision, fondée sur une logique dominant-dominé et posant par nature un jugement de valeur, a d'abord été remise en question par le développement de la littérature comparée. Béatrice Joyeux rappelle cependant que la littérature comparée se limite souvent, aujourd'hui encore, à " poser l'existence de littératures nationales distinctes par essence puis à les dépasser, en construisant de manière artificielle un niveau métanational (celui des similitudes et des caractères universels) ${ }^{6}$ ". Cette approche tend en effet à mettre "l'accent sur les différences, oubliant l'importance des métissages ${ }^{7}$ ». Sans les réfuter totalement, la théorie des transferts culturels dépasse ces deux méthodes en se fondant, comme le souligne à juste titre Martin Doré, sur la conviction que « tout transfert d'une culture à l'autre déclenche forcément un processus d'adaptation qui rend caduc tout comparatisme basé sur du même ${ }^{8}$ ». De fait, les échanges culturels s'établissent entre des aires culturelles nécessairement distinctes, même si le poids symbolique de certaines peut être plus grand que pour d'autres, en raison notamment de leur capacité à s'imposer comme culture «dominante ${ }^{9} »$.

6 Béatrice Joyeux, «Les transferts culturels : un discours de la méthode ", Hypothèses, $\mathrm{n}^{\circ} 1$ (2002), p. 150-151.

7 Ibid.

8 Martin Doré, «Fonctionnement du transfert culturel et examen d'un cas francocanadien dans le marché du livre, 1970-2000 ", dans Marie-Pier Luneau et al. (dir.), Passeurs d'histoire(s): figures des relations France-Québec en histoire du livre, Québec, Les Presses de l'Université Laval, 2010, coll. «Cultures québécoises », p. 444-445.

9 Sur cette question, voir Pascale Casanova, La république mondiale des lettres, Paris, Seuil, 2008. 
Face à la notion d'influence, le concept de transfert culturel parait, en somme, plus vaste et plus efficace. Il permet, précise Doré, "d'avoir une vision dynamique des changements qui surviennent dans une culture puisqu'il tient compte non seulement du résultat final, mais aussi du processus en entier, avec son origine, son contenu et les agents ayant procédé au déplacement et à l'intégration de l'objet ${ }^{10}$ ». Pour autant, le terme " influence " n'a pas disparu du champ lexical des chercheurs intéressés par les transferts culturels, au point d'ailleurs de donner parfois l'impression que les deux termes sont utilisés comme des synonymes. De fait, la théorie des transferts culturels n'a pas la vocation d'exclure la notion d'influence du vocabulaire de l'historien : pour Jacques Thuillier, l'influence est « directement liée à l'œuvre d'art, et il ne saurait être question de [la] rejeter ${ }^{11}$ ». C'est cependant une notion complexe, que l'« on croit trop facilement simple et d'évidence immédiate ${ }^{12}$ ". Elle doit donc être révisée ou plutôt, complétée. La notion de transfert apparaît à ce titre plus pertinente, car elle dépasse la question de l'identification des possibles emprunts - une approche certes érudite, mais parfois réductrice - pour privilégier l'étude de la circulation des agents de diffusion et des mécanismes d'appropriation, en s'attachant autant que possible à l'analyse de contacts concrets et mesurables entre les cultures. Par rapport à la notion d'influence, qui laisse entendre que les innovations culturelles sont le fruit d'une démarche passive, voire qu'elles sont simplement subies par la société d'accueil, celle de transfert culturel montre qu'il s'agit plutôt d'une démarche volontaire. Elle met ainsi en lumière la dimension dynamique des échanges entre les cultures et en fait un véritable processus de (re)création.

Létude des transferts culturels apparait ainsi comme un modèle très valable, spécialement dans les disciplines que sont l'histoire, la

10 Doré, «Fonctionnement du transfert culturel et examen d'un cas franco-canadien dans le marché du livre, 1970-2000 », p. 446.

11 Jacques Thuillier, Théorie générale de l'histoire de l'art, Paris, Odile Jacob, 2003, p. 130.

12 Ibid. 
philosophie, les études littéraires et l'histoire de l'art, domaine dans lequel on privilégie volontiers le terme de transfert artistique. Dans les études québécoises, la théorie des transferts culturels s'est développée à partir de la seconde moitié des années 1990, mais elle reste encore relativement peu exploitée. Des chercheurs rassemblés autour de Laurier Turgeon, Denys Delâge et Réal Ouellet ont élargi le champ d'application de cette approche pour englober les sociétés non européennes et étudier les transferts culturels à l'œuvre entre l'Europe et l'Amérique depuis le $\mathrm{XVI}^{\mathrm{e}}$ siècle $^{13}$. Robert Dion a analysé la construction d'une référence allemande chez les auteurs de la revue Liberté, fondée en $1959^{14}$. Pour sa part, Jean Morency, qui envisage les fondements pluriculturels des littératures canadiennes d'expression française, s'est notamment intéressé aux passeurs culturels entre le Canada français et les États-Unis au cours des années 1920-193015. Dans ses travaux sur la culture médiatique au Canada francophone, Hans-Jürgen Lüsebrink a également étudié les almanachs des XIX ${ }^{\mathrm{e}}$ et $\mathrm{xx}^{\mathrm{e}}$ siècles comme des phénomènes d'interculturalité ${ }^{16}$. Plus récemment, le collectif Passeurs d'histoire(s) s'est intéressé au cas de médiateurs qui, par l'intermédiaire du livre et de l'imprimé, ont

13 Laurier Turgeon, "De l'acculturation aux transferts culturels ", dans Laurier Turgeon, Denys Delâge et Réal Ouellet (dir.), Transferts culturels et métissages : Amérique/Europe, $X V I^{e}-X X^{e}$ siècle, Paris, L'Harmattan; Québec, Les Presses de l’Université Laval, 1996, p. 11-20.

14 Robert Dion, L'Allemagne de Liberté : sur la germanophilie des intellectuels québécois, Ottawa, Les Presses de l'Université d'Ottawa; Würzburg, Königshausen \& Neumann, 2007, coll. "Transferts culturels".

15 Jean Morency, «La (re)découverte de l'Amérique : le rôle de quelques médiateurs culturels dans le Québec de l'entre-deux-guerres ", dans Jean Morency et al. (dir.), Des cultures en contact : visions de l'Amérique du Nord francophone, Québec, Nota bene, 2005, p. 299-311; "Connaissance de la littérature américaine au Québec, de la traduction à l'intégration ", dans Robert A. Stebbins, Claude Romney et Micheline Ouellet (dir.), Francophonie et langue dans un monde divers en évolution: contacts interlinguistiques et socioculturels, Winnipeg, Presses universitaires de Saint-Boniface, 2003, p. 185-196.

${ }^{16}$ Hans-Jürgen Lüsebrink, "L'interculturalité dans la culture médiatique au Canada francophone prémoderne, $\mathrm{XIX}^{\mathrm{e}}$-début $\mathrm{XX}^{\mathrm{e}}$ siècle : l'exemple des almanachs canadiens-français ", dans Morency et al. (dir.), Des cultures en contact, p. 129-148. 
œuvré à maintenir les relations entre le Québec et la France actives, et ce, depuis l'époque de la Nouvelle-France jusqu'à nos jours ${ }^{17}$. Par leur caractère interdisciplinaire, ces divers travaux invitent à élargir l'analyse des transferts culturels à l'ensemble des pratiques artistiques du Canada français.

C'est à partir de cette approche méthodologique que nous avons invité les auteurs du présent dossier à se pencher sur les facteurs endogènes et exogènes qui viennent transformer la vie culturelle de la première moitié du $\mathrm{xx}^{\mathrm{e}}$ siècle au Canada français. Il s'agissait plus précisément de saisir la dynamique des échanges interculturels avec d'autres sociétés de référence, notamment française et états-unienne, qui constituent alors deux pôles importants pour les acteurs culturels. Envisagée du point de vue de l'histoire culturelle, la théorie des transferts culturels nous semble particulièrement efficace pour saisir les transformations que connaît la culture canadienne-française à partir du tournant $\mathrm{du} \mathrm{xx}^{\mathrm{e}}$ siècle, alors que les élites intellectuelles entreprennent de repenser le rapport de celle-ci au modèle hégémonique français et que la société canadienne-française entre dans une phase de modernisation, dont témoignent les phénomènes d'urbanisation, d'industrialisation et d'immigration massive auxquels on assiste à cette époque. L'étude des transferts culturels permet de décrire comment, à partir de quelles références et selon quelles stratégies, se renouvellent les pratiques artistiques de la première moitié du $\mathrm{Xx}^{\mathrm{e}}$ siècle.

Les analyses qui composent le présent dossier ont toutes en commun de porter sur des biens et des pratiques culturels que l'histoire littéraire et l'histoire de l'art ont longtemps jugés « mineurs » : il s'agit de phénomènes populaires se rapportant davantage à la culture de masse qu'au champ de production restreinte, pour reprendre un

17 Marie-Pier Luneau et al. (dir.), Passeurs d'histoire(s) : figures des relations FranceQuébec en histoire du livre, Québec Les Presses de l'Université Laval, 2010, coll. "Cultures québécoises". 
concept cher au sociologue Pierre Bourdieu ${ }^{18}$. Ainsi, dans l'optique de l'histoire culturelle, les auteurs ne posent pas de jugement de valeur sur les pratiques culturelles envisagées : ils s'intéressent à des objets ou des passeurs qui ont joué un rôle important au sein de la société canadienne-française de l'époque, en tenant compte du décalage qui pouvait alors exister entre le discours dominant et les pratiques culturelles elles-mêmes.

C'est ce que nous montre l'article de Denis Saint-Jacques et Marie-José des Rivières qui porte sur le cas du magazine, une forme médiatique largement diffusée au début $\mathrm{du} \mathrm{xx}^{\mathrm{e}}$ siècle qui semble, à première vue, avoir conservé une homogénéité de structure et de contenu, malgré le fait qu'elle ait circulé à travers différentes aires culturelles. Revenant d'abord sur la façon dont les États-Unis ont réussi à imposer un modèle axé sur la publicité, tant dans les pays européens comme la France et l'Angleterre, pourtant à l'origine de ce média, qu'au Canada français, les auteurs tentent ensuite de saisir la spécificité du magazine canadien-français. Bien que différents acteurs du champ culturel canadien-français affirment, dans les années 1910, 1920 et 1930, que les magazines produits localement ne sont qu'une copie du modèle américain, Saint-Jacques et des Rivières constatent que le contexte sociopolitique propre au Canada français, de même que le maintien de la relation de dépendance culturelle envers l'ancienne métropole favorisent plutôt l'apparition d'une forme médiatique hybride et, partant, originale : si le support reste typiquement américain, l'imaginaire, véhiculé notamment à travers les récits de fiction, se révèle, lui, essentiellement français.

Simon-Pierre Beaudet et Chantal Savoie s'intéressent, pour leur part, aux vecteurs à la fois culturels et intermédiatiques par lesquels une chanson à succès comme J'attendrai, d'origine italienne, circule dans différentes aires géoculturelles et comment elle est adaptée au contexte local. Partant, pour ce faire, des demandes des auditrices de

18 Pierre Bourdieu, Les règles de l'art : genèse et structure du champ littéraire, Paris, Seuil, 1998. 
la radio dans les années 1940, les auteurs s’attardent aux différentes transformations subies par la chanson afin de montrer l'originalité de la version qui circule en sol canadien-français. Loin d'être une simple reprise de la version étrangère, la chanson est littéralement recréée pour s'adapter aux goûts du public local. Beaudet et Savoie montrent, par ailleurs, que les modèles culturels étrangers ne sont pas les seuls à influer sur les pratiques culturelles locales : celles-ci connaissent également une transformation du fait de leur circulation entre les différents niveaux de la hiérarchie culturelle. Passant du champ de production restreinte au champ de grande production, la chanson J'attendrai subit ainsi une forme d'acculturation qui en fait une production symbolique nouvelle.

L'article de Brigitte Nadeau aborde un cas de double transfert culturel, rappelant ainsi que les échanges culturels s'opèrent rarement à sens unique. L'abbé Albert Tessier, pionnier du cinéma documentaire québécois, s'est beaucoup intéressé à l'histoire régionale, plus particulièrement à celle de sa Mauricie natale. Il n'est donc pas étonnant qu'il ait cherché, comme le montre Nadeau, à promouvoir auprès de ses interlocuteurs français une image renouvelée du Québec traditionnel, inspirée par le régionalisme de Frédéric Mistral, mais adaptée à ses propres objectifs de propagande. Cette représentation toute personnelle d'un Québec à la fois catholique, rural, voire sauvage, et pourtant ancré dans le présent, trouve un écho dans les préoccupations de certains auteurs français venus chercher en Mauricie des témoignages de cette société idéale, héritage direct de la France prérévolutionnaire. Assumant pleinement son rôle de passeur culturel, Tessier veille à leur fournir les preuves de l'existence de cette « sociétémémoire " dont il se fait le promoteur enthousiaste. Il adopte pour ce faire des stratégies qui contribueront sans doute à sa reconnaissance en France, où il reçoit en 1959 le Prix de la langue française de l'Académie française et la médaille de la Ville de Paris pour son rôle dans la diffusion de la pensée française au Canada.

De son côté, Dominic Hardy suit de manière originale la présence diffuse de la pensée polémique de l'écrivain français Léon Bloy dans 
le discours culturel canadien-français des années 1940 et 1950. En effet, selon l'auteur, le contexte sociopolitique étouffant de cette période empêche que s'exprime haut et fort l'écho de la pensée bloyenne dans les écrits de certains intellectuels canadiens-français pourtant majeurs. Partant d'une caricature que Robert LaPalme réalise de Maurice Duplessis en 1958, soit à la fin du long règne politique de ce dernier, Hardy montre qu'il est possible de retracer l'influence souterraine, mais persistante, de Bloy au Québec en suivant le fil celui de la satire au sens large, tant littéraire que graphique - qui relie Olivar Asselin à LaPalme, en passant par Claude-Henri Grignon. Cet angle d'analyse lui permet de cerner les manifestations d'un esprit contestataire propre au contexte canadien-français sous le régime de Duplessis. On constate ainsi qu'Asselin y fait figure de passeur culturel puisque c'est en quelque sorte par lui que LaPalme est initié aux écrits bloyens. L'analyse de la caricature de Duplessis permet ainsi d'envisager les transferts culturels à travers la notion de trace ou d'écho d'une référence culturelle étrangère adaptée au contexte sociopolitique et culturel du Québec des années 1950.

En somme, les deux premiers articles qui composent ce dossier portent sur des formes culturelles (le magazine et la chanson à succès), tandis que les deux derniers s'intéressent au rôle de personnes qui agissent comme passeurs entre deux cultures. Ces textes ont d'abord fait l'objet de communications prononcées à l'occasion de la journée d'études que nous avions organisée en collaboration avec le Centre de recherche interuniversitaire sur la littérature et la culture québécoises (CRILCQ) de l'Université de Montréal le 25 mai 2010. Cette journée d'échanges scientifiques s'inscrivait dans le cadre des travaux de l'équipe de recherche "Penser l'histoire de la vie culturelle ", qui envisage la culture artistique au Québec de la fin du XIX ${ }^{\mathrm{e}}$ siècle aux années 1950 selon une approche interdisciplinaire. Celle-ci s'illustre aujourd'hui de manière concrète, tant du point de vue des auteurs du présent dossier, issus de diverses disciplines, que des articles publiés, qui portent sur des objets au croisement de différentes pratiques culturelles. 